\title{
Identification of BACE2 as an avid ß-amyloid-degrading protease
}

\author{
Samer O Abdul-Hay, Tomoko Sahara, Melinda McBride, Dongcheul Kang and Malcolm A Leissring*
}

\begin{abstract}
Background: Proteases that degrade the amyloid B-protein (Aß) have emerged as key players in the etiology and potential treatment of Alzheimer's disease (AD), but it is unlikely that all such proteases have been identified. To discover new Aß-degrading proteases (AßDPs), we conducted an unbiased, genome-scale, functional cDNA screen designed to identify proteases capable of lowering net Aß levels produced by cells, which were subsequently characterized for Aß-degrading activity using an array of downstream assays.

Results: The top hit emerging from the screen was $ß$-site amyloid precursor protein-cleaving enzyme 2 (BACE2), a rather unexpected finding given the well-established role of its close homolog, BACE1, in the production of Aß. BACE2 is known to be capable of lowering Aß levels via non-amyloidogenic processing of APP. However, in vitro, BACE2 was also found to be a particularly avid AßDP, with a catalytic efficiency exceeding all known AßDPs except insulin-degrading enzyme (IDE). BACE1 was also found to degrade Aß, albeit 150-fold less efficiently than BACE2. $A B$ is cleaved by BACE2 at three peptide bonds-Phe19-Phe20, Phe20-Ala21, and Leu34-Met35-with the latter cleavage site being the initial and principal one. BACE2 overexpression in cultured cells was found to lower net $A B$ levels to a greater extent than multiple, well-established AßDPs, including neprilysin (NEP) and endothelinconverting enzyme-1 (ECE1), while showing comparable effectiveness to IDE.

Conclusions: This study identifies a new functional role for BACE2 as a potent ABDP. Based on its high catalytic efficiency, its ability to degrade Aß intracellularly, and other characteristics, BACE2 represents a particulary strong therapeutic candidate for the treatment or prevention of $A D$.
\end{abstract}

Keywords: Amyloid-ß-protein, Alzheimer disease, ß-site APP-cleaving enzyme-1, ß-site APP-cleaving enzyme-2, Functional screen, Gene therapy, Protease, Proteolytic degradation

\section{Background}

Alzheimer disease (AD) is a progressive and presently incurable neurodegenerative disorder characterized by abnormal accumulation of the amyloid $\beta$-protein $(A \beta)$ in brain regions important for mnemonic and cognitive functions. $A ß$ is a heterogeneous mixture of peptides ranging from 37 to 43 amino acids in length [1] produced via sequential cleavage of the amyloid precursor protein (APP) by BACE1 and the presenilin $/ \gamma$-secretase complex [2-4]. Autosomal-dominant mutations in 3 genes-APP and presenilin-1 and -2-are known to cause rare, familial forms of $\mathrm{AD}$ either by increasing the production of all forms of $A ß$ or by increasing the relative production of longer, more amyloidogenic forms,

\footnotetext{
* Correspondence: leissring@mayo.edu

Department of Neuroscience, Mayo Clinic, 4500 San Pablo Road, Birdsall Bldg., Rm. 117, Jacksonville, FL 32224, USA
}

such as Aß42 [5]. Nevertheless, the precise mechanisms underlying sporadic $\mathrm{AD}$, which makes up the vast majority of cases, remain to be elucidated.

$A ß$-degrading proteases (AßDPs) are potent regulators of cerebral $A ß$ levels and, as such, represent important players in the etiology and potential treatment of $\mathrm{AD}$ [6]. Amyloidogenesis and downstream cytopathology can be attenuated and even completely prevented by enhancing the activity of any of several AßDPs, while, conversely, genetic deletion of one or more AßDPs leads to significant elevations in cerebral Aß [7]. Significantly, patients with sporadic $A D$ were recently shown to exhibit defects in the clearance of $A ß$ (rather than increases in its production) [8] and, in light of the large body of evidence implicating AßDPs in the regulation of cerebral $A ß$ levels [7], it is reasonable to infer that defects in one or more AßDPs could contribute to

\section{Biomed Central}


impaired $A ß$ clearance. While more than twenty proteases are now known to degrade $A ß[7]$, these were not identified through any systematic approach, but instead emerged haphazardously from a disconnected set of largely serendipitous discoveries. Nevertheless, essentially all $A ß D P s$ now known to regulate $A ß$ in vivo were originally identified through exclusively in vitro or cellbased approaches [9].

To discover new AßDPs more systematically, we conducted an unbiased, cell-based, functional screen of 352 proteases in the human genome. The top Aß-lowering protease emerging from this screen was $B$-site APPcleaving enzyme-2 (BACE2) [10]. Previous studies have shown that BACE2 can lower Aß levels via $\alpha$-secretaselike cleavage of APP within the Aß sequence [11-16], an activity that has been dubbed " $\theta$-secretase" [17]. However, we found that BACE2 is also a remarkably avid AßDP, with a catalytic efficiency exceeding all other known AßDPs except insulin-degrading enzyme (IDE).

\section{Results and discussion}

\section{Functional screen for novel AßDPs}

To identify novel AßDPs, we performed a cell-based functional screen using a commercial library consisting of 352 full-length, sequence-verified, human cDNAs encoding diverse members of all protease classes. We experimented with several approaches before settling on a final configuration for the primary screen. Assays designed to monitor degradation of exogenous $A ß$ were found to be confounded by the highly dominant effect of IDE, which mediates the vast majority of extracellular $A ß$ degradation in cultured cells [18-20]. Transient transfection of cDNAs into cell lines stably expressing APP was also tried, but this approach suffered from incomplete transfection efficiency, which attenuated the effect on net extracellular $A ß$ levels. We therefore elected to conduct the screen by co-transfecting protease-encoding cDNAs, together with positive and negative controls, into a rodent cell line ( $\mathrm{CHO}$ cells) together with a plasmid encoding wild-type human APP fused to alkaline phosphatase (AP) (see Figure 1A; Methods). Use of the APP-AP construct ensured that human A $\beta$ production was limited to cells also expressing candidate AßDPs, while also providing an internal control for transfection efficiency (via AP activity). Importantly, the co-transfection strategy also increased the likelihood of detecting $A ß D P s$ that degrade $A ß$ intracellularly, prior to its secretion, in addition to those that act exclusively extracellularly. Cytotoxicity was also quantified via an MTT conversion assay, but no significant cell death was detected so these data were not incorporated into subsequent analyses. The screen was performed in quadruplicate and, for each well, the ratio of Aß40 concentration to AP activity was calculated, then normalized to appropriate intra-plate controls (Figure 1B).

From among the 352 proteases examined, by far the largest decrease in normalized $A ß$ levels $(97 \pm 1.2 \%)$ was induced by BACE2, which was in fact the only protease to lower $A ß$ levels more than $75 \%$, our pre-determined cut-off for viable hits (Figure 1B).

\section{BACE2 transfection lowers $A \beta$ levels}

To confirm and extend the results obtained in the cDNA screen, we compared the degree to which overexpression of BACE2 and its homolog BACE1 [21] affected the net production of different $A ß$ species. Consistent with the results of the primary screen, BACE2 transfection in $\mathrm{CHO}$ cells decreased the levels of both $\mathrm{A} \beta 40$ and A $\beta 42$ (Figure 1C). Overexpression of BACE1 in this cell type, by contrast, had no effect on net $A B$ levels (Figure 1C). We note that BACE1 overexpression would not be expected to increase $A ß$ production in $\mathrm{CHO}$ cells, since previous studies have established that $\gamma$-secretase, rather than $B$-secretase, is the rate-limiting step in $A B$ production in this cell type [22].

\section{$B A C E 2$ and $B A C E 1$ degrade $A B$ in vitro}

Expression of BACE2 in cells could lower Aß levels either directly, via proteolytic degradation, or indirectly, via alternative mechanisms such as hydrolysis of APP or APP C-terminal fragments (CTFs) [11-16]. To distinguish these possibilities, we tested the ability of recombinant BACE2 to hydrolyze synthetic $A ß$ in vitro, using a well-established fluorescence polarization-based $A ß$ degradation assay [23]. Recombinant BACE2 was found to avidly degrade $A ß$ in this paradigm, confirming that BACE2 is indeed a bona fide AßDP (Figure 2A). Recombinant $B A C E 1$ also hydrolyzed $A ß$, indicating that it too is an AßDP (Figure 2B). However, BACE1 was much less efficient than BACE2, requiring $24 \mathrm{~h}$ to degrade $A ß$ to a similar extent as was achieved following a 10-min incubation with BACE2 (Figure 2B). Based on these results, the efficiency of BACE1 would appear to be 150 -fold lower than that of BACE2.

\section{BACE2-mediated A degradation is $\mathrm{pH}$-dependent}

As an aspartyl protease, the catalytic efficiency of BACE2 is expected to be pH-dependent. To confirm this, we compared the rate of hydrolysis of Aß40 across a range a $\mathrm{pH}$ values. Consistent with expectations, BACE2 was found to be maximally effective at $\mathrm{pH} 3.5$ (Figure 2C), and decreasingly effective at higher $\mathrm{pH}$ values. These findings strongly suggest that BACE2 would not be operative at the cell surface or within the extracellular space. 


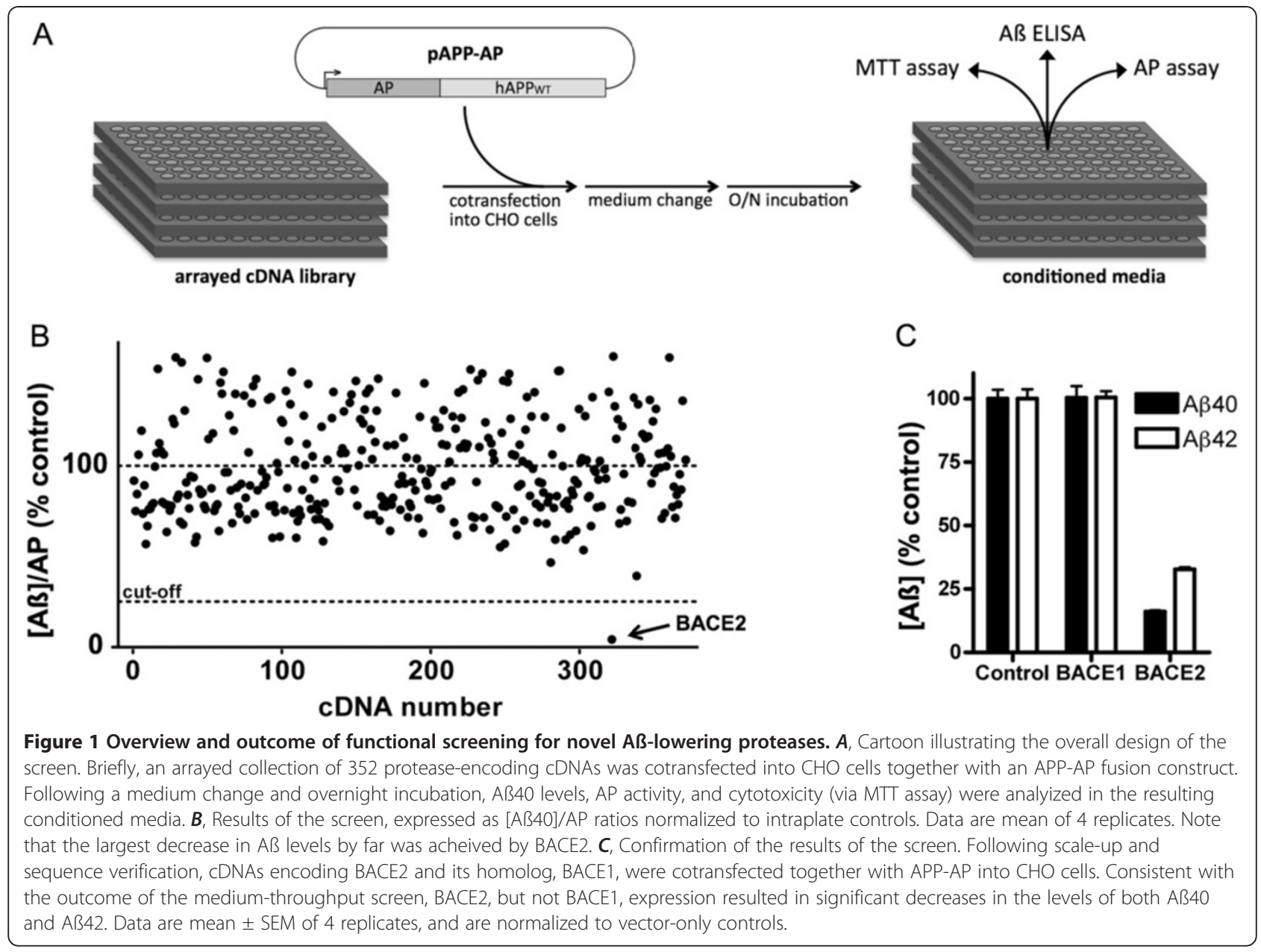

\section{BACE2 does not degrade fibrillar $A ß$}

Individual AßDPs can be categorized in terms of their ability or inability to degrade fibrillar forms of Aß. Many well-established AßDPs, such as IDE and NEP, avidly degrade monomeric $\mathrm{A} ß$ but cannot degrade fibrillar forms and are therefore categorized as pure peptidases. Others, such as plasmin, degrade $A ß$ fibrils and thus can also be categorized as fibrilases [7]. To determine to which category BACE2 belongs, we incubated recombinant BACE2 with pre-formed fibrils of Aß42 and quantified the degree of aggregation by thioflavin $\mathrm{T}$ fluorescence. No significant reduction in aggregation was observed, even following incubation at $37^{\circ} \mathrm{C}$ for up to $3 \mathrm{~d}$ (Figure 2D). These results suggest that, as is true for the majority of AßDPs [7], BACE2 does not degrade Aß fibrils.

\section{BACE2 cleaves $A ß$ at 3 sites}

We next investigated which peptide bond(s) within $A \beta$ are hydrolyzed by BACE2 and BACE1. To that end, we co-incubated N-terminally biotinylated A $\beta 40$ or $A \beta 42$ (300nM) with BACE2 (5 nM) and analyzed the products by immunoprecipitation/mass spectrometry (IP/MS) (see Methods). Within $1 \mathrm{~h}$, BACE2 almost completely hydrolyzed both $A ß$ species, generating the shorter fragment, A 334 , in both cases (Figure 3A-D). To test whether any additional cleavages can occur, we incubated N-terminally biotinylated A 340 (300 nM) with a larger amount of BACE2 (25 nM) for 1 and $24 \mathrm{~h}$. At these higher concentrations and longer incubation times, $A \beta 19$ and $A \beta 20$ were the principal N-terminal fragments remaining at the end of the reaction (Figure 3E-F). Collectively, these in vitro results suggest that BACE2 cleaves $A \beta$ at three different positions: Phe19-Phe20, Phe20-Ala21, and Leu34-Met35, with the latter cleavage site being the initial and principal one, as is consistent with previous observations $[13,14,24]$.

To confirm whether BACE2 cleaves $A \beta$ at the same sites in a more physiological setting, we analyzed $A ß$ species in the conditioned media of cells expressing APP-AP either alone or together with BACE2 by IP/MS (see Methods). As expected for cells expressing APP-AP alone, the medium from these cells contained $\mathrm{A} \beta 42$, $\mathrm{A} \beta 40, \mathrm{~A} \beta 39, \mathrm{~A} \beta 38$, and $\mathrm{A} \beta 37$ (Figure 4A). BACE2 

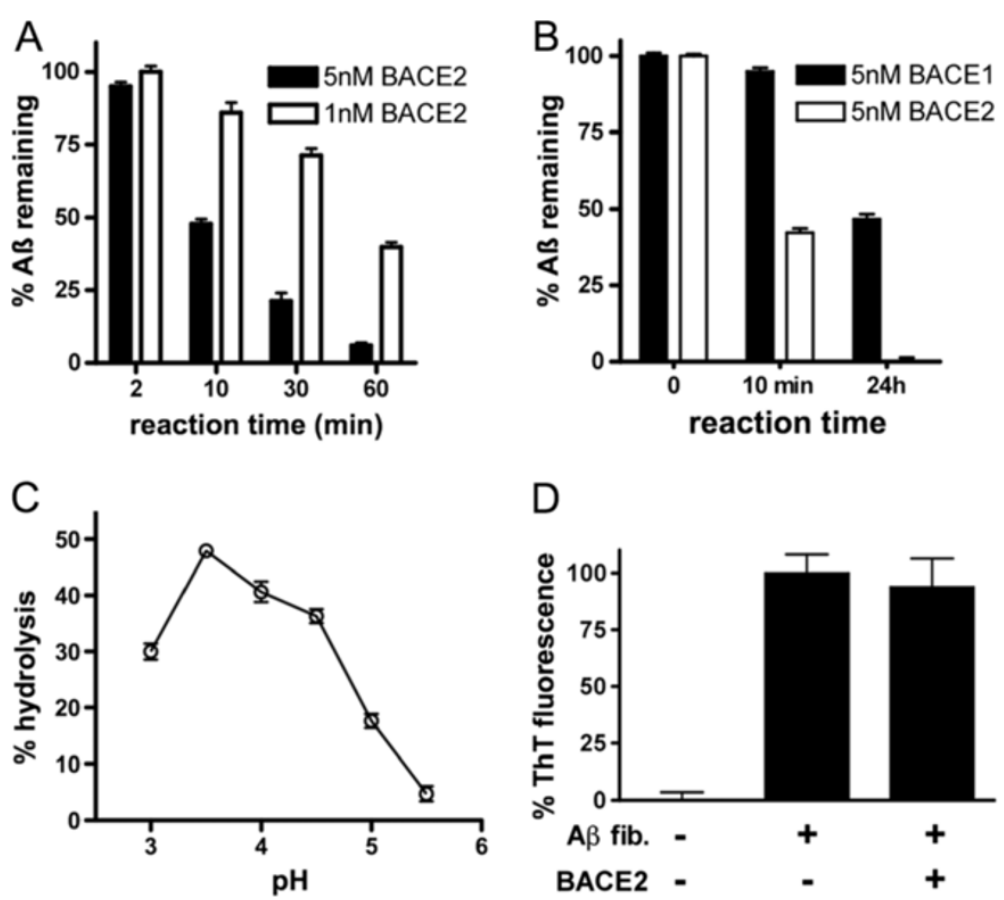

Figure 2 BACE2 degrades $A B$ in vitro. $A$, Percent $A ß$ remaining following incubation with different concentrations of recombinant $B A C E 2$ for various lengths of time. Data are mean \pm SEM of 4 replicates, normalized to protease-free controls. $\boldsymbol{B}$, Comparison the relative $A ß$-degrading ability of recombinant BACE2 vs. BACE1. Note that $24 \mathrm{~h}$ incubation with BACE1 was required to achieve approximately the same extent of degradation as effected by BACE2 in $10 \mathrm{~min}$. Data are mean \pm SEM of 3 replicates, normalized to protease-free controls. $C$, BACE2 activity is pH dependent. Percent Aß degradation catalyzed by equivalent amounts of BACE2 at different $\mathrm{pH}$ values. Data are mean \pm SEM of 4 replicates. $D$, BACE2 does not degrade fibrillar Aß. Lack of effect of BACE2 (10 nM) on preformed Aß42 fibrils following incubation at $37^{\circ} \mathrm{C}$ for $5 \mathrm{~d}$, as determined by thioflavin $T$ fluorescence. Data are mean \pm SEM of 3 replicates.

expression suppressed the signal of all of these species, and new peaks corresponding to $A \beta 19, A \beta 20$, and $A \beta 34$ emerged (Figure $4 \mathrm{~B}$ ), confirming that the cleavage sites mediated by BACE2 in vitro are also hydrolyzed in intact cells. The appearance of Aß34 is particularly notable, because cleavage at position 34 can only occur after production of full-length $A ß$, as this peptide bond is positioned within the transmembrane domain of APP, as has been shown previously [24]. Although this result clearly indicates that BACE2 does indeed degrade $A ß$ after it is produced, it is not possible to quantify the extent to which the Aß19 and Aß20 peaks are the result of $\theta$-secretase activity or subsequent degradation of the $\mathrm{A} ß 34$ fragment (or full-length $\mathrm{A} ß$ ). As a consequence, it is difficult to estimate the exact extent to which the Aßlowering effect of BACE2 can be assigned to nonamyloidogenic processing versus $A ß$ degradation per se in experimental paradigms of this type.

\section{BACE2 degrades $A ß$ more efficiently than well-established AßDPs}

Having established BACE2 as an AßDP, we next investigated how BACE2 compares to other known AßDPs in terms the ability to degrade $A ß$ in vitro and to lower net
$A ß$ levels in cells. To compare the relative efficiency of BACE2 in vitro, we monitored the degradation of a fixed amount of $\mathrm{Aß}(200 \mathrm{nM})$ by recombinant BACE2 (5 nM) as compared to equal quantities of several wellestablished AßDPs, including IDE, NEP and plasmin. Under these conditions, BACE2 hydrolyzed Aß more efficiently than all other AßDPs except IDE (Figure 5A). We note that the concentration of $A ß$ used in this experiment was considerably lower than the $K_{\mathrm{M}}$ for each of the proteases tested (see [23] and below), making the initial velocity of this reaction a good index of the relative catalytic efficiency.

\section{Kinetics of $A ß$ degradation by BACE2}

To investigate the catalytic efficiency of BACE2 more quantititatively, we determined the kinetics of degradation of both Aß40 and Aß42 by BACE2 (see Methods). For this analysis, we were careful to use freshly prepared batches of monomeric human $A \beta 40$ and $A \beta 42$ peptides, which we routinely prepare by size-exclusion chromatography and which have been extensively characterized $[25,26]$. BACE2 cleaved both Aß species with similar kinetics, exhibiting apparent $K_{\mathrm{M}}$ values in the low micromolar range and albeit with apparent $k_{\text {cat }}$ values slightly 


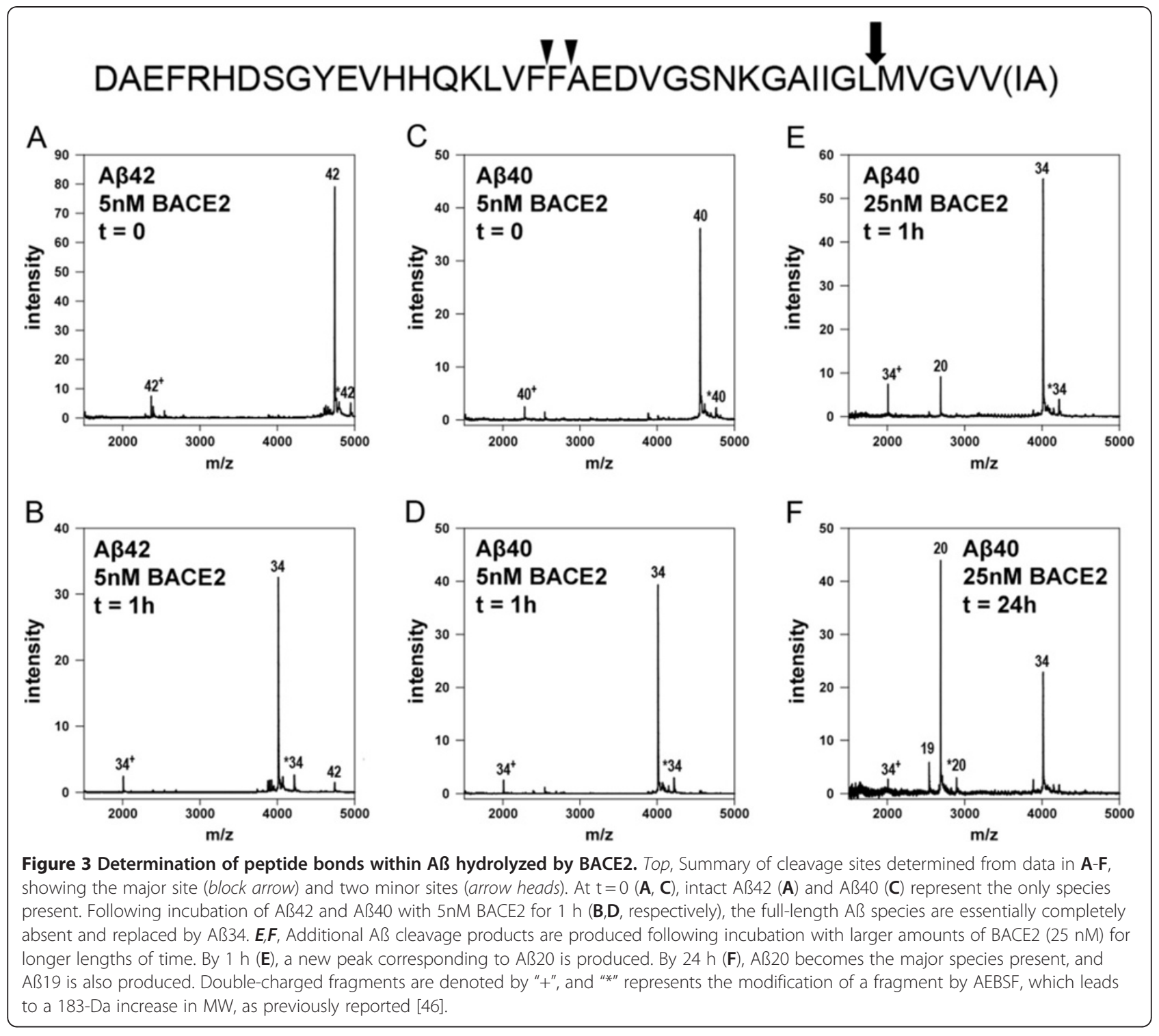

higher for $\mathrm{A} ß 40$ relative to $\mathrm{A} 342\left(0.135 \pm 0.016 \mathrm{~min}^{-1}\right.$ and $0.025 \pm 0.005 \mathrm{~min}^{-1}$, respectively; Table 1$)$. In terms of catalytic efficiency $\left(k_{\mathrm{cat}} / K_{\mathrm{M}}\right)$, BACE2 degrades $\mathrm{A} \beta 40$ approximately 4-fold more efficiently than A $\beta 42$ (Table 1). These parameters exceed the published values for most other well-characterized AßDPs, including NEP [23], ECE1 [27], and plasmin [23], while being comparable to those of IDE $[23,28]$. Consequently, these values are in good agreement with the side-by-side comparison of $A ß$ degradation in vitro discussed above (Figure $5 \mathrm{~A}$ ).

To investigate the relative ability of BACE2 to lower $\mathrm{A} ß$ levels under more physiological conditions, we cotransfected $\mathrm{CHO}$ cells with APP together with BACE2 or several other AßDPs, then quantified net $A ß 40$ and Aß42 levels in the conditioned medium by ELISA. We emphasize that this approach cannot control for intrinsic differences in transcription or translation efficiency, and, in the case of BACE 2, the Aß-lowering effect can also be mediated to an undetermined degree by BACE2-mediated $\theta$-secretase activity. Nevertheless, the results were in good agreement with the in vitro findings: BACE2 lowered net $\mathrm{A} ß 40$ and $\mathrm{A} 42$ levels to a comparable extent as IDE, with both of the latter being significantly more effective than NEP or plasmin (Figure 5B, C).

\section{BACE2 colocalizes with $A \beta$ intracellularly}

Having determined that BACE2 is functionally among the most efficient AßDPs yet discovered, we subsequently investigated the subcellular localization of BACE2, focusing in particular on the extent to which it colocalizes with $A \beta$ in acidic compartments, where BACE2 is expected to be operative. In agreement with other published findings [29], application of fluorescently tagged $A ß$ to live cells resulted in its 

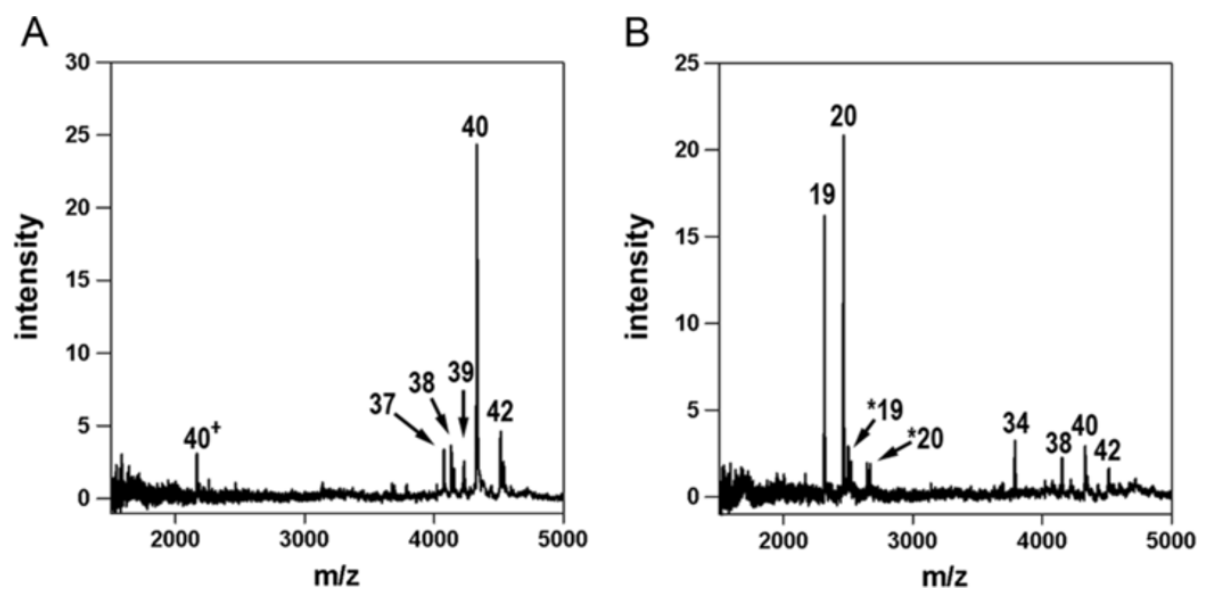

Figure 4 Overexpression of $B A C E 2$ in cells yields $A ß$ fragments identical to those produced in vitro. $A, B$, Spectra of $A ß$ fragments determined by IP/MS analysis of the conditioned media of CHO cells transfected with APP and empty vector (A) or APP and BACE2 (B) (see Methods). $\boldsymbol{A}$, APP expression alone produces peaks corresponding to $A ß 42, A ß 40, A B 39, A B 38$ and $A B 37$. $\boldsymbol{B}$, Co-expression of APP and BACE2 results in decreases in the relative abundance of the aforementioned $A B$ species and the appearance of three new fragments: $A B 34, A B 20$ and Aß19. Double-charged fragments are denoted by " + ", and "**" represents the modification of a fragment by AEBSF, which leads to a 183-Da increase in MW, as previously reported [46].

accumulation at intracellular sites largely overlapping with lysosomes (Figure 6A). To test whether BACE2 is also localized to lysosomes and/or other compartments containing $\mathrm{A} ß$, we analyzed $\mathrm{CHO}$ cells expressing BACE2 tagged at its N-terminus with green fluorescent protein (BACE2-GFP). As determined by confocal microscopy, BACE2-GFP was found to be present in lysosomes (Figure $6 \mathrm{~B}$ ) and also to overlap significantly with fluorescently labeled $A ß$ (Figure 6C).

\section{BACE2 degrades $A ß$ at intracellular sites}

To directly assess whether BACE2 degrades $A ß$ at intracellular sites, we tested the ability of BACE2-expressing cells to degrade exogenously applied $A ß$ by multiple methods. Cells overexpressing BACE2-GFP and loaded with fluorescently tagged Aß40 showed significantly reduced intracellular $A ß 1 \mathrm{~h}$ after washing, but this was not the case for cells overexpressing GFP alone (Figure 7A). Consistent with this, levels of intracellular $A ß$, both fluorescently tagged and unmodified, were found to be consistently lower in cells overexpressing (untagged) BACE2 relative to vector-trasfected controls (Figure 7B,C). Notably, significantly lower levels of intracellular $A ß$ were observed both $5 \mathrm{~min}$ and $2 \mathrm{~h}$ after washing in multiple paradigms. Collectively, these results strongly suggest that $\mathrm{BACE} 2$ is a bona fide $\mathrm{A} B \mathrm{DP}$ that avidly degrades $A ß$ within acidic compartments.

\section{Conclusions}

One of the most fruitful outcomes of the genomic revolution is the emergence of genome-scale collections of full-length, sequence verified cDNAs. Combined with appropriate functional assays, cDNA libraries have catalyzed significant advances in our understanding of AD pathogenesis, including the seminal discovery that $B$-secretase activity, the first step in the production of $A ß$, is mediated by BACE1 [21]. Here, we utilized a similar approach to discover new candidate AßDPs, using a functional assay sensitive to both extracellular and intracellular $A ß$ degradation (as well as other potential Aß-lowering mechanisms). Rather unexpectedly, the top hit emerging from a screen of 352 proteases was BACE2, a close homo$\log$ of BACE1. Subsequent characterization confirmed that, in addition to BACE2's established ability to lower $A ß$ production via $\theta$-secretase-mediated processing of APP [11-16], BACE2 also avidly degrades Aß with a catalytic efficiency exceeding almost all well-established AßDPs.

The finding that BACE2 is an avid AßDP suggests a novel and unexpected role for this protease in the pathogenesis of $\mathrm{AD}$. Indeed, given its close homology with BACE1, it was initially hypothesized that BACE2 might mediate the production of $A ß$, via $\beta$-secretase cleavage of APP, instead $[15,16]$. However, most evidence now suggests that BACE2 does not contribute appreciably to $A ß$ production in vivo [3]. For instance, cultured neurons from BACE2 knockout mice did not show reductions in $A ß$ following transfection with APP [30] and conversely, overexpression of BACE2 in APP transgenic mice failed to increase cerebral $A ß$ levels, as would be expected if BACE2 possessed $ß$-secretase-like activity.

In addition to its potent ability to degrade $\mathrm{A} \beta, \mathrm{BACE} 2$ also possesses a second $A ß$-lowering function for 

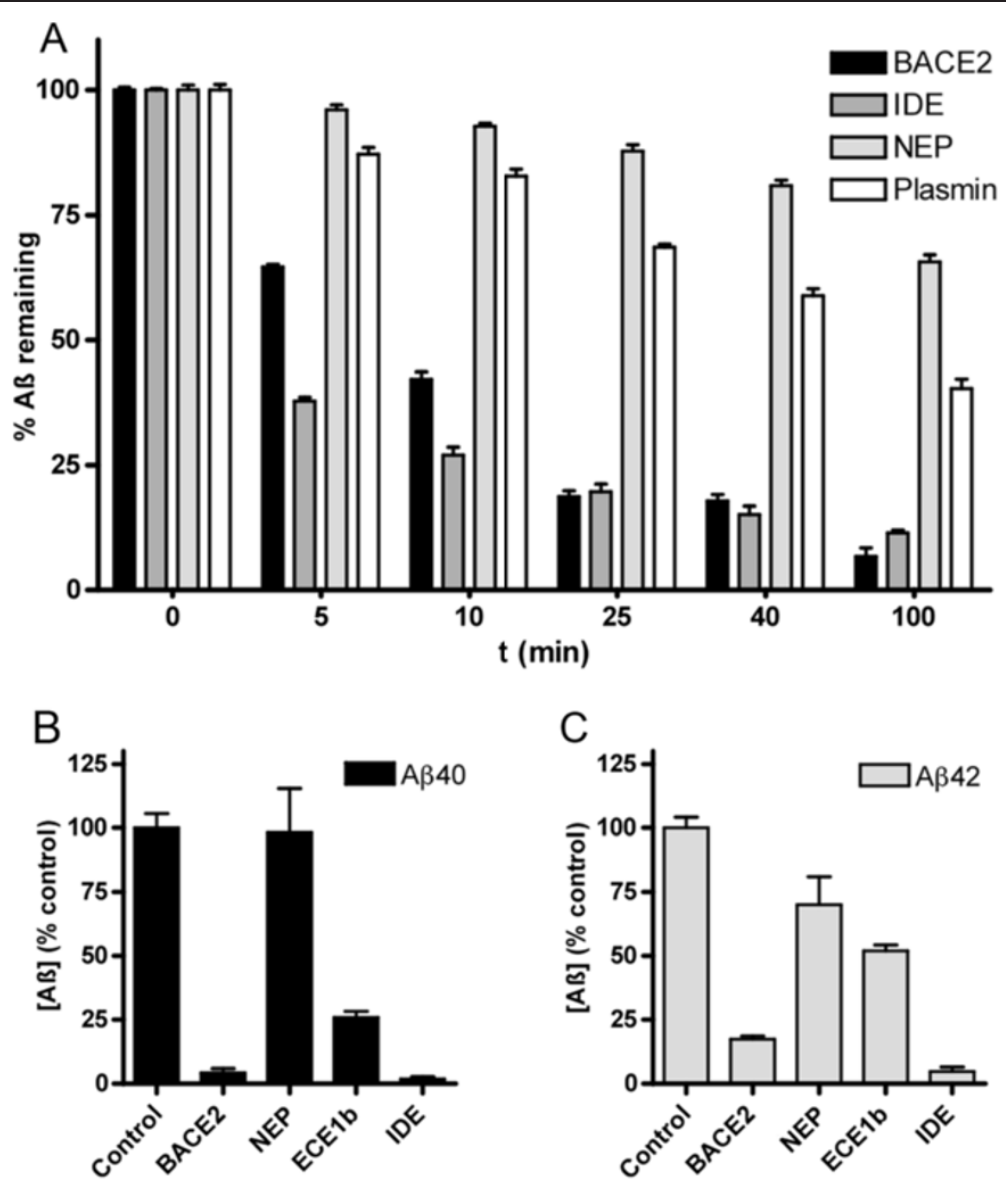

Figure 5 Comparison of the efficacy of BACE2 relative to other well-established AßDPs in vitro and in cultured cells. $A$, Degradation of $A B$ in vitro by equivalent nominal concentrations $(5 \mathrm{nM})$ of recombinant BACE2, IDE, NEP and plasmin. Note that BACE2 degrades $A B$ at a faster rate than NEP and plasmin, but not IDE. $B, C$, Effects on $A ß 40(\mathbf{A})$ and $A ß 42(\mathbf{C})$ levels following cotransfection of CHO cells with APP together with equivalent quantities of CDNAs encoding BACE2, ECE1b and IDE. In good agreement with the results in vitro (A), BACE2 lowers the levels of both $A ß$ species to an extent exceeding NEP and ECE1b, but comparable to IDE. Data are mean \pm SEM of 4 replications, normalized to controls cotransfected with empty vector $\left(V_{0}\right)$.

BACE2, one that is quite independent of $A ß$ degradation. Specifically, BACE2 has been shown to cleave APP and the $ß$-secretase-derived APP-CTF within the Aß sequence, in a manner analogous to $\alpha$-secretase [11-16]. This activity, dubbed $\theta$-secretase [17], occurs at positions 19 and 20 within the $A ß$ sequence, precisely the same cleavage sites identified in the present study $[13,14]$. As is true for $\alpha$-secretase, $\theta$-secretase activity lowers $A ß$ levels by shuttling APP away from the amyloidogenic processing pathway [11-16].

Table 1 Kinetic parameters of $A ß 40$ and $A ß 42$ degradation by BACE2

\begin{tabular}{|c|c|c|}
\hline & $\mathrm{A} ß 40$ & $\mathrm{~A} 42$ \\
\hline$K_{\mathrm{M}}(\mu \mathrm{M})$ & $2.8 \pm 0.7$ & $2.3 \pm 0.6$ \\
\hline$V_{\max }\left(\mu M \min ^{-1}\right)$ & $0.68 \pm .083$ & $0.12 \pm 0.025$ \\
\hline$k_{\text {cat }}\left(\min ^{-1}\right)$ & $0.135 \pm 0.016$ & $0.025 \pm 0.005$ \\
\hline$k_{\text {cat }} / K_{M}\left(M^{-1} \min ^{-1}\right)$ & $4.82 \times 10^{7}$ & $1.07 \times 10^{7}$ \\
\hline
\end{tabular}

As confirmed by previous work [24], we found that BACE2 also cleaves $A ß$ at the Leu34-Met35 peptide bond, which was in fact the initial and principal site of cleavage. Notably, cleavage at this position can only occur after production of full length $A ß$ by $B$ - and $\gamma$-secretase, because this peptide bond in APP or in APP CTFs is normally embedded within the cell membrane [24]. This fact, together with the finding that Aß34 is produced in cells overexpressing of BACE2 and APP, provides clear evidence that the Aß-degrading activity of BACE2 contributes significantly to the overall $A ß$-lowering effect of BACE2 overexpression, even in the context of concurrent $\theta$-secretase activity.

Given that BACE2 can lower Aß both by decreasing its production and by mediating its degradation, which of these mechanisms are relevant to the pathogenesis or the potential treatment of AD? The answer depends critically on precisely where and to what extent BACE2 is expressed in vivo. Although BACE2 protein is readily 

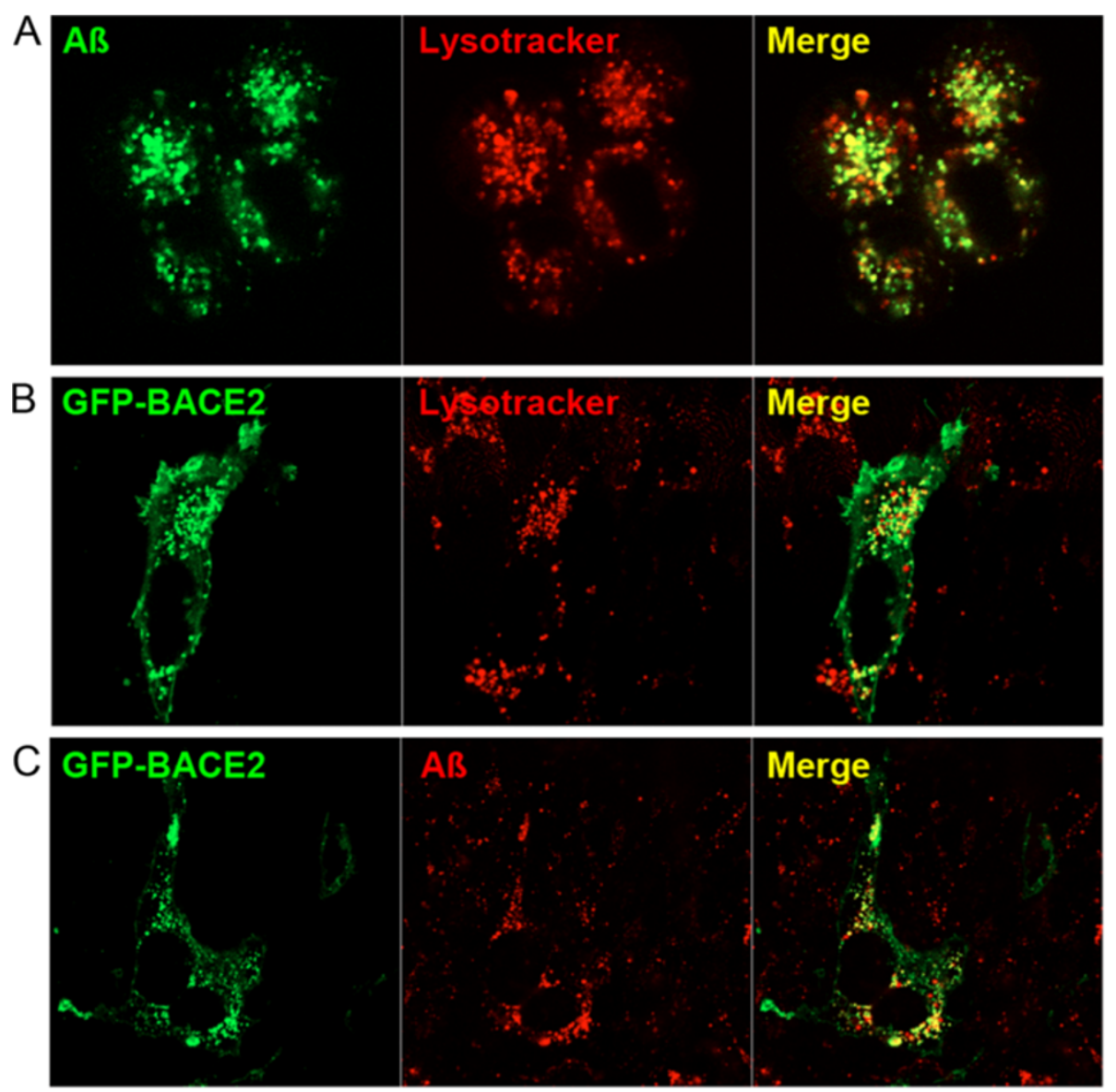

Figure 6 BACE2 is localized to intracellular compartments relevant to Aß degradation. $\boldsymbol{A}$, Exogenous administration of fluorescently labeled Aß40 (green) to CHO cells results in accumulation at intracellular sites overlapping with lysosomes, as labelled by Lysotracker Red (red) and visualized by confocal microscopy. $\boldsymbol{B}$, BACE2 is expressed in multiple intracellular compartments, including lysosomes. Distribution of GFPtagged BACE2 (green) in cells labeled with Lysotracker Red (red) shows significant localization within lysosomes (yellow). C, BACE2 colocalizes with exogenously administered Aß. Confocal images showing significant overlap (yellow) between BACE2 (green) and fluorescently labeled Aß (red). For these experiments, cells were imaged within 5 minutes of washing in cold PBS to remove medium containing excess fluorescently labeled Aß. Note that the the majority of BACE2-GFP-expressing cells contianed very low levels of fluorescent Aß (see Figure 7), and the particular cell shown exhibited relatively high levels of internalized $A$ B, allowing us to highlight the overlap with BACE2.

detected in brain extracts [15,30-36], and its activity has even been shown to be comparable to that of BACE1 in post-mortem brain $[31,33]$, there is conflicting evidence about which cell types express BACE2. Studies in mice, on the one hand, suggest that the protease is expressed abundantly in glia but only minimally in neurons [30]. To the extent that these findings apply to humans, $\theta$-secretase cleavage of APP by BACE2 would be unlikely to play any significant pathophysiological role in $\mathrm{AD}$, given that APP itself is expressed predominantly in neurons, with only modest expression levels in nonneuronal brain cells [31]. On the other hand, multiple studies in post-mortem human brain tissue have reported detectable BACE2 expression not only in astrocytes, but also in neurons [15,33], suggesting that the $\theta$-secretase activity of BACE2 may, to some extent, contribute to the overall economy of brain $A ß$. The pathophysiological relevance of BACE2's function as an AßDP is similarly difficult to predict and likewise dependent on the extent to which the protease is expressed in neurons. Astrocytes are known mediate the clearance of $A ß$ [37], but the contribution of intra-astrocytic $A ß$ degradation relative to intraneuronal or extracellular degradation in vivo remains to be established. As was true for other AßDPs first identified in cells [9], the answer to these questions will require further study in relevant animal models.

Notwithstanding uncertainty about its role in $\mathrm{AD}$ pathogenesis, a number of considerations suggest that BACE2 represents an especially strong therapeutic candidate, particularly for gene therapy-based approaches. BACE2 can lower Aß catalytically via two independent mechanisms, and its Aß-degrading ability alone exceeds that of most other AßDPs, some of which are being 


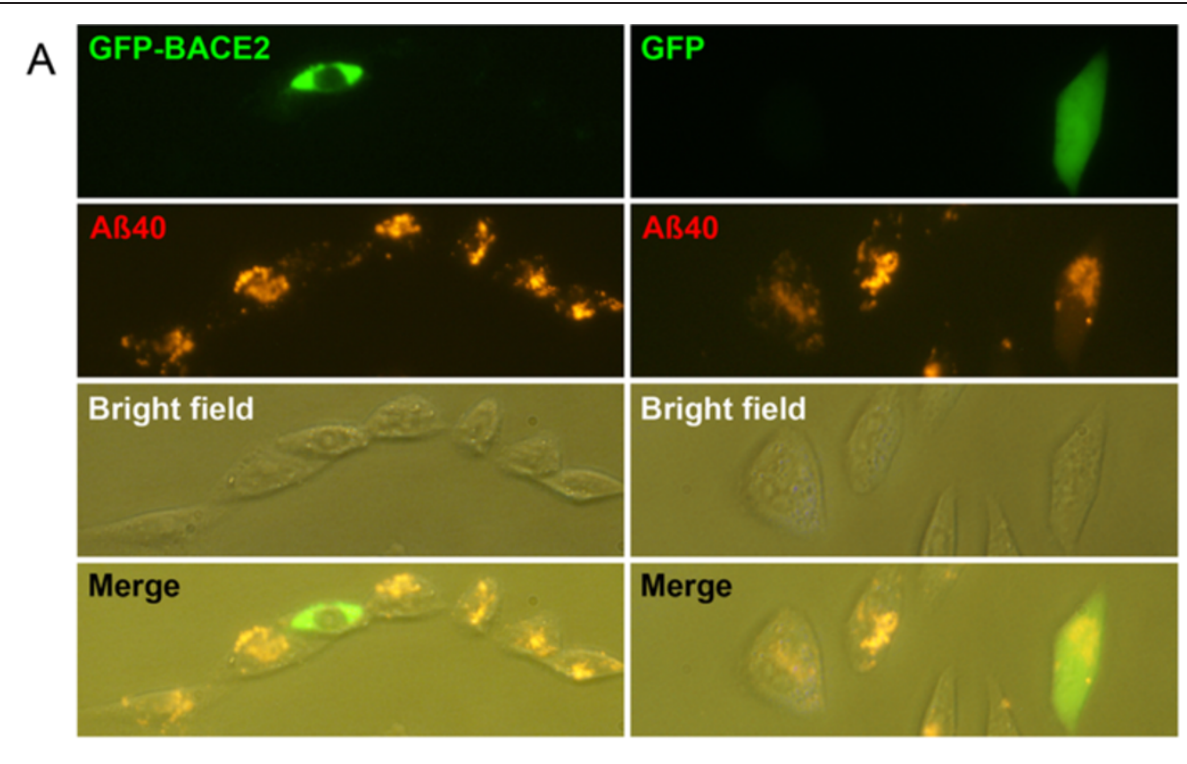

B

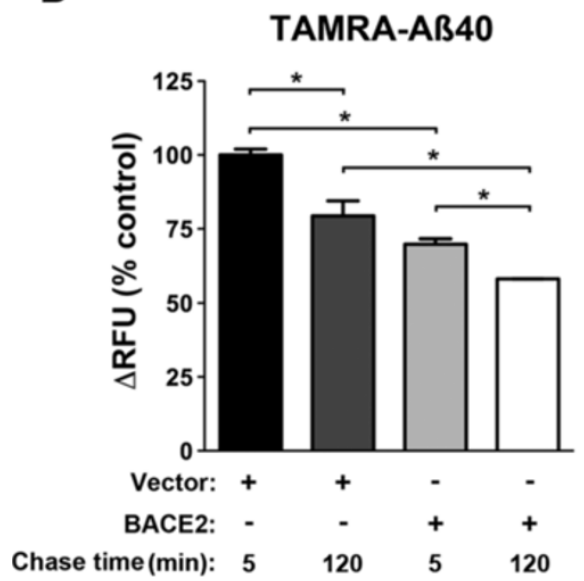

C

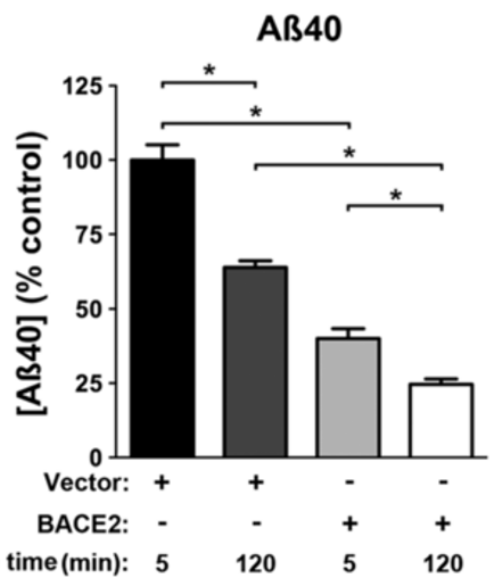

Figure 7 BACE2 degrades $A ß$ at intracellular sites. $A$, CHO cells expressing GFP-BACE2 (green, left), but not those expressing GFP alone (green, right), exhibit marked reductions in intracellular $A B$ (red). For these experiments, cells were loaded for $6 \mathrm{~h}$ with $400 \mathrm{nM}$ fluorescently labeled $A ß 40$, washed, then incubated at $37^{\circ} \mathrm{C}$ for $1 \mathrm{~h}$ prior to imaging by conventional fluorescence microscopy. $\boldsymbol{B}, \boldsymbol{C}, \mathrm{BACE} 2$ overexpression significantly lowers intracellular Aß. B. Quantification of intracellular pools of fluorescently labeled Aß40 in CHO cells 0 and 2 hours after loading. $\boldsymbol{C}$, Relative levels of intracellular (unmodified) Aß40 in CHO cells 0 and 2 hours after loading, as quantified by ELISA. Data are mean \pm SEM of 3 replicates, normalized to vector-only controls. ${ }^{*} P<0.05$ by Tukey's multiple comparisons test.

considered for gene therapy clinical trials [38]. Moreover, as an aspartyl protease, BACE2 possesses distinct advantages relative to other AßDPs. First, it is operative with subcellular compartments most relevant to $A ß$ production-i.e., those containing active $\beta$ - and $\gamma$-secretase, which are both aspartyl proteases-thus allowing it to impact $A ß$ levels prior to secretion. In this connection, there is growing evidence that intracellular $A ß$ may represent an especially pathogenic role in $A D$ [39], so modulation of this pool may be particularly appropriate therapeutically. Second, because BACE2 is operative exclusively at intracellular sites, its expression could be readily restricted to the site of administration. This is in contrast to many other AßDPs which are secreted and/ or active extracellularly $[19,40,41]$ and thus less capable of being confined to specific regions.

In conclusion, this study identifies BACE2 as a novel and highly efficient AßDP. This newly identified function of BACE2, together with its established ability to also lower $A ß$ production via $\theta$-secretase activity, suggests that BACE2 may play a significant role in $\mathrm{AD}$ pathogenesis. Moreover, even if BACE2 plays no role in the etiology of $\mathrm{AD}, \mathrm{BACE} 2$ nevertheless represents a particularly attractive candidate for gene therapeutic approaches to the treatment of prevention of this presently incurable disease. 


\section{Methods}

\section{cDNA screening}

A library of 352 full-length, sequence verified, human cDNAs encoding diverse members of all protease classes was purchase from a commercial source (OriGene Technologies, Inc.) in 96-well format (100 ng/well). For negative and positive controls, a subset of blank wells on each plate were supplemented with empty vector or a construct expressing a well-established AßDP, human ECE1b [27], respectively (100 ng/well). As a source of human $\mathrm{A} ß$ and also as a transfection control, each well was cotransfected with a hybrid construct, APP-AP (60 ng/well), comprised of a vector expressing wild-type human APP fused at its N-terminus with alkaline phosphatase (AP) [42]. Additional blank wells were left untreated for cell-free background controls. $\mathrm{CHO}$ cells (4.8 $\times 10^{4} /$ well) suspended in DMEM/Opti-MEM supplemented with $5 \% \mathrm{FBS}$ were then co-transfected with APP-AP and protease-encoding cDNAs using Fugene 6.0, according to manufacturer's recommendations (Promega Corp.). Transfected cells were allowed to grow overnight under standard cell culture conditions (5\% $\mathrm{CO}_{2} ; 37^{\circ} \mathrm{C} ; 95 \%$ humidity) then the medium was exchanged. $24 \mathrm{~h}$ later, the conditioned media were collected for downstream analysis (see below). All experiments were conducted in compliance with and with approval by the Mayo Clinic Institutional Review Board.

\section{AP activity}

Following heat treatment to inactivate endogenous phosphatases $\left(65^{\circ} \mathrm{C}\right.$ for $\left.15 \mathrm{~min}\right)$ present in the media, conditioned media ( $30 \mu \mathrm{L} /$ well) was added to 96 -well plates containing AP substrate, 4-nitrophenylphosphate $(170 \mu \mathrm{L} /$ well, $2 \mathrm{mg} / \mathrm{mL}$ ), dissolved in AP buffer (1 M diethanolamine, $0.5 \mathrm{mM} \mathrm{MgCl}_{2}, 10 \mathrm{mM}$ L-homoarginine, $\mathrm{pH}$ 9.8). Plates were incubated for $30 \mathrm{~min}$ and AP activity was determined from absorbance $\left(\mathrm{OD}_{405}\right)$ using a Spectra$\mathrm{Max}^{\circledR} \mathrm{M}^{\mathrm{e}}$ multilabel plate reader (Molecular Devices).

\section{$A \beta$ ELISA}

$A \beta$ levels were quantified using a sandwich ELISA system based on antibody pairs 33.1.1/13.1.1 for $A \beta 40$ and 2.1.3/4 G8 for A $\beta 42$ as described previously [43]. Conditioned media were supplemented with Complete ${ }^{\mathrm{TM}}$ Protease Inhibitor Cocktail (Roche) just after collection and analyzed immediately. For experiments quantifying intracellular Aß, cells were plated in in 96-well plates $\left(2 \times 10^{4}\right.$ cells per well) and transfected with BACE2encoding cDNA or empty vector, washed, then incubated with $400 \mathrm{nM}$ synthetic $\mathrm{A} ß$ for $6 \mathrm{~h}$. After washing with PBS, intracellular Aß was extracted with $5 \mathrm{M}$ guanidinium isothiocyanate and quantified using a commercially available ELISA (Wako Chemicals USA, Inc.) after 10 -fold dilution in the manufacturer-provided dilution buffer.

\section{Mass spectrometry}

The cleavage sites within $A \beta 40$ and $A \beta 42$ hydrolyzed by BACE2 and BACE1 were determined essentially as described [44] with minor modifications. Briefly, $A \beta$ peptides or biotinylated $A \beta$ peptides were incubated for various lengths of time with recombinant BACE2 enzyme in Assay Buffer (25 mM acetate buffer, pH 4.0, supplemented with $0.1 \%$ BSA). The reaction was stopped by addition of protease inhibitor cocktail and $\mathrm{pH}$ adjustment. $A \beta$ fragments were immediately precipitated by magnetic beads coated with streptavidin (for biotinylated $\mathrm{A} \beta$ ) or magnetic beads coated with Ab9 antibody [45] (for unmodified $A \beta$ ). Beads were washed with $10 \mathrm{mM}$ $\mathrm{NH}_{4} \mathrm{CO}_{3}, \mathrm{pH} 8.0$, and peptide fragments were eluted using $0.5 \%$ trifluoroacetic acid in $75 \%$ acetonitrile in water, followed by the addition of an equal volume of a saturated sinapic acid solution dissolved in $0.5 \%$ trifluoroacetic acid in 50\% acetonitrile and water. Digested products were spotted onto a gold chip, dried, and analyzed using a Ciphergen ProteinChip SELDI time-of-flight system (Bio-Rad). Mass spectra were acquired automatically in a linear positive mode at 1350 shots per spectrum. Peptides containing a183-Da increase in MW were identified as being modified by AEBSF, as previously reported [46]. Same procedure was applied to detect the endogenous $\mathrm{A} \beta$ fragments produced by $\mathrm{CHO}$ cells transfected with APP and BACE2 (using Ab9 as a capture antibody).

\section{In vitro analyses of $A \beta$ degradation by BACE2}

The kinetics of $A \beta 40$ and $A \beta 42$ degradation by BACE2 were determined using freshly prepared, monomeric $A \beta$ peptides separated from aggregated species by size-exclusion chromatography and characterized as described [25,26]. A $\beta$ peptides were diluted in neutral Dilution Buffer (20 mM Tris, pH 8.0 supplemented with $0.1 \%$ BSA) and reactions were initiated by transfer into 20 times more volume of Assay Buffer supplemented with purified recombinant BACE2 (R\&D Systems, nominal concentration 1 or $5 \mathrm{nM}$ ) or, as a control for non-specific loss of $A \beta$, the latter buffer lacking BACE2. Where required, reactions were terminated by supplementation with protease inhibitor cocktail and adjustment to neutral $\mathrm{pH}$. For ELISA-based experiments, $A \beta 42$ and $A \beta 40$ were quantified using the sandwich ELISAs described above. For determination of kinetic parameters, ELISAs were used to quantify the initial velocities of degradation of a range of different concentrations of Aß40 (0.2 to $16 \mu \mathrm{M})$ or Aß42 (0.6 to $16 \mu \mathrm{M})$ by a fixed amount of recombinant BACE2 $(5 \mathrm{nM})$ in Assay Buffer, and $K_{\mathrm{M}}$ and $v_{\max }$ values 
were determined in triplicate by fitting a hyperbolic curve to these data in Prism 5.0 (GraphPad Software, Inc.). For determination of the $\mathrm{pH}$ dependence of $\mathrm{A} \beta$ degradation, experiments were carried same as described above, using Assay Buffer at different $\mathrm{pH}$ values $(3.0,3.5,4.0,4.5,5.0,5.5)$. The reactions were stopped at $10 \mathrm{~min}$ and the remaining $200 \mathrm{nM}$ of $\mathrm{A} \beta$ was determined using a well-characterized fluorescence polarization-based activity $A ß$ degradation assay, as described [23]. For comparison of the rate of degradation of $A \beta$ by different proteases, we incubated $200 \mathrm{nM}$ of $\mathrm{A} \beta$ fluorescent substrate (FA $\beta B$ ) with $5 \mathrm{nM}$ of different protease in their corresponding buffers: BACE1 and BACE2 using Assay Buffer and IDE, NEP, and plasmin in PBS, pH 7.4 supplemented with $0.1 \%$ BSA. The reactions were stopped by addition of protease inhibitor cocktail, 500nM streptavidin, and adjustment to neutral $\mathrm{pH}$. The degree of $\mathrm{A} \beta$ hydrolysis was immediately determined using a polarization-based $A ß$ degradation assay [23]. Recombinant BACE2 (R\&D Systems) and plasmin (EMD Biosciences) were purchased from commercial sources, while recombinant IDE and secreted NEP (i.e., lacking the transmembrane domain) were generated and purified as described [23]. All reactions were performed at $37^{\circ} \mathrm{C}$.

\section{Fluorescence microscopy}

$\mathrm{CHO}$ cells $\left(10^{6}\right.$ cells $\left./ \mathrm{cm}^{2}\right)$ were plated onto 8-well polyD-lysine-coated, glass-bottom chambers (MatTek Corp.) in culture medium (DMEM/Opti-MEM supplemented with 5\%FBS). For BACE2 transfections, cell were transfected with a construct encoding BACE2 tagged at its C-terminus with GFP (OriGene Technologies, Inc. Cat. No. RG04860) using Fugene 6.0 transfection reagent according to manufacturer's recommendations (Promega Corp.). For $A \beta$ colocalization experiments, cells were washed twice in fresh culture medium, then incubated in the latter medium supplemented with either Aß40 (500 nM) labeled at the N-terminus with HiLight Fluor $^{\mathrm{TM}} 488$ or HiLight Fluor ${ }^{\mathrm{TM}} 555$ (AnaSpec, Inc.). For lysosomal staining, cells were incubated with Lysotracker Red according to manufacturer's recommendations (Invitrogen Corp.), then washed 2 times with fresh culture medium prior to imaging. For confocal microscopy, cells were washed with fresh medium then imaged immediately using the 488-nm and 543-nm laser lines on a Zeiss LCM 510 META confocal microscope (Carl Zeiss, Inc.). Images were processed and analyzed using MetaMorph software according to manufacturer's recommendations (Molecular Devices, Inc.). For conventional fluorescence microscopy of intracellular Aß, cells were washed with fresh medium, then incubated at $37^{\circ} \mathrm{C}$ for $1 \mathrm{~h}$ prior to imaging using a Nikon Labophot 2 fluorescent microscope (Nikon Inc.).

\section{Abbreviations}

Aß: Amyloid B-protein; AßDP: Aß-degrading protease; AD: Alzheimer disease; AP: Alkaline phosphatase; APP: Amyloid precursor protein; BACE1: B-site APPcleaving enzyme-1; BACE2: ß-site APP-cleaving enzyme-2; ECE1: Endothelinconverting enzyme-1; IDE: Insulin-degrading enzyme; NEP: Neprilysin.

\section{Competing interests}

The authors declare they have no competing interests.

\section{Authors' contributions}

SA-H contributed to the design of experiments, executed the screen and all follow up experiments, analyzed data, and drafted the manuscript. TS assisted with the execution of the primary screen. MM and DK assisted with the maintenance of cell cultures. ML conceived of the experimental approach, designed experiments, analyzed data and wrote the manuscript. All authors read and approved the final manuscript.

\section{Acknowledgements}

We thank Dr. Terrone Newberry and William Tay for providing monomeric and fibrillar Aß peptides and Drs. Todd Golde and Kevin Felsenstein for contributing the APP-AP construct. Supported by a grant from the Coins For Alzheimer's Trust Fund to ML.

Received: 16 March 2012 Accepted: 16 August 2012

Published: 17 September 2012

\section{References}

1. Selkoe DJ: Translating cell biology into therapeutic advances in Alzheimer's disease. Nature 1999, 399:A23-A31.

2. Vassar R: Beta-secretase (BACE) as a drug target for Alzheimer's disease. Adv Drug Deliv Rev 2002, 54:1589-1602.

3. De Strooper B, Vassar R, Golde T: The secretases: enzymes with therapeutic potential in Alzheimer disease. Nat Rev Neurol 2010, 6:99-107.

4. Wolfe MS: The gamma-secretase complex: membrane-embedded proteolytic ensemble. Biochemistry 2006, 45:7931-7939.

5. Mucke L: Neuroscience: Alzheimer's disease. Nature 2009, 461:895-897.

6. Eckman EA, Eckman CB: Abeta-degrading enzymes: modulators of Alzheimer's disease pathogenesis and targets for therapeutic intervention. Biochem Soc Trans 2005, 33:1101-1105.

7. Leissring MA, Saido TC: Degradation of amyloid-ß protein. In The biology of Alzheimer disease. Edited by Selkoe DJ, Mandelkow E, Holtzman DM. Cold Spring Harbor, New York: Cold Spring Harbor Laboratory Press; 2011:387-404.

8. Mawuenyega KG, Sigurdson W, Ovod V, Munsell L, Kasten T, Morris JC, Yarasheski KE, Bateman RJ: Decreased clearance of CNS beta-amyloid in Alzheimer's disease. Science 2010, 330:1774.

9. Leissring MA: The ABCs of Aß-cleaving proteases. J Biol Chem 2008, 283:29645-29649.

10. Acquati F, Accarino M, Nucci C, Fumagalli $P$, Jovine L, Ottolenghi S, Taramelli R: The gene encoding DRAP (BACE2), a glycosylated transmembrane protein of the aspartic protease family, maps to the down critical region. FEBS Lett 2000, 468:59-64.

11. Shi XP, Tugusheva K, Bruce JE, Lucka A, Wu GX, Chen-Dodson E, Price E, Li $Y, X u M$, Huang $Q$, et al: Beta-secretase cleavage at amino acid residue 34 in the amyloid beta peptide is dependent upon gamma-secretase activity. J Biol Chem 2003, 278:21286-21294.

12. Basi G, Frigon N, Barbour R, Doan T, Gordon G, McConlogue L, Sinha S, Zeller M: Antagonistic effects of beta-site amyloid precursor proteincleaving enzymes 1 and 2 on beta-amyloid peptide production in cells. $J$ Biol Chem 2003, 278:31512-31520.

13. Yan R, Munzner JB, Shuck ME, Bienkowski MJ: BACE2 functions as an alternative alpha-secretase in cells. J Biol Chem 2001, 276:34019-34027.

14. Fluhrer R, Capell A, Westmeyer G, Willem M, Hartung B, Condron MM, Teplow DB, Haass C, Walter J: A non-amyloidogenic function of BACE-2 in the secretory pathway. J Neurochem 2002, 81:1011-1020.

15. Hussain I, Powell DJ, Howlett DR, Chapman GA, Gilmour L, Murdock PR, Tew DG, Meek TD, Chapman C, Schneider K, et al: ASP1 (BACE2) cleaves the amyloid precursor protein at the beta-secretase site. Mol Cell Neurosci 2000, 16:609-619.

16. Farzan M, Schnitzler CE, Vasilieva N, Leung D, Choe H: BACE2, a beta -secretase homolog, cleaves at the beta site and within the amyloid- 
beta region of the amyloid-beta precursor protein. Proc Natl Acad Sci USA 2000, 97:9712-9717.

17. Sun $X$, He G, Song W: BACE2, as a novel APP theta-secretase, is not responsible for the pathogenesis of Alzheimer's disease in Down syndrome. FASEB J 2006, 20:1369-1376.

18. Qiu WQ, Walsh DM, Ye Z, Vekrellis K, Zhang J, Podlisny MB, Rosner MR, Safavi A, Hersh LB, Selkoe DJ: Insulin-degrading enzyme regulates extracellular levels of amyloid beta-protein by degradation. $J$ Biol Chem 1998, 273:32730-32738.

19. Qiu WQ, Ye Z, Kholodenko D, Seubert P, Selkoe DJ: Degradation of amyloid beta-protein by a metalloprotease secreted by microglia and other neural and non-neural cells. J Biol Chem 1997, 272:6641-6646.

20. Vekrellis K, Ye Z, Qiu WQ, Walsh D, Hartley D, Chesneau V, Rosner MR, Selkoe DJ: Neurons regulate extracellular levels of amyloid beta-protein via proteolysis by insulin-degrading enzyme. J Neurosci 2000, 20:1657-1665

21. Vassar R, Bennett BD, Babu-Khan S, Kahn S, Mendiaz EA, Denis P, Teplow DB, Ross S, Amarante P, Loeloff R, et al: Beta-secretase cleavage of Alzheimer's amyloid precursor protein by the transmembrane aspartic protease BACE. Science 1999, 286:735-741.

22. Kimberly WT, LaVoie MJ, Ostaszewski BL, Ye W, Wolfe MS, Selkoe DJ: Gamma-secretase is a membrane protein complex comprised of presenilin, nicastrin, Aph-1, and Pen-2. Proc Natl Acad Sci USA 2003, 100:6382-6387.

23. Leissring MA, Lu A, Condron MM, Teplow DB, Stein RL, Farris W, Selkoe DJ: Kinetics of amyloid beta-protein degradation determined by novel fluorescence- and fluorescence polarization-based assays. J Biol Chem 2003, 278:37314-37320.

24. Fluhrer R, Multhaup G, Schlicksupp A, Okochi M, Takeda M, Lammich S, Willem M, Westmeyer G, Bode W, Walter J, Haass C: Identification of a beta-secretase activity, which truncates amyloid beta-peptide after its presenilin-dependent generation. J Biol Chem 2003, 278:5531-5538.

25. Nichols MR, Moss MA, Reed DK, Lin WL, Mukhopadhyay R, Hoh JH, Rosenberry TL: Growth of beta-amyloid(1-40) protofibrils by monomer elongation and lateral association. Characterization of distinct products by light scattering and atomic force microscopy. Biochemistry 2002, 41:6115-6127.

26. Rangachari V, Moore BD, Reed DK, Sonoda LK, Bridges AW, Conboy E, Hartigan D, Rosenberry TL: Amyloid-beta(1-42) rapidly forms protofibrils and oligomers by distinct pathways in low concentrations of sodium dodecylsulfate. Biochemistry 2007, 46:12451-12462.

27. Eckman EA, Reed DK, Eckman CB: Degradation of the Alzheimer's amyloid beta peptide by endothelin-converting enzyme. J Biol Chem 2001, 276:24540-24548.

28. Perez A, Morelli L, Cresto JC, Castano EM: Degradation of soluble amyloid beta-peptides $1-40,1-42$, and the Dutch variant $1-40 \mathrm{Q}$ by insulin degrading enzyme from Alzheimer disease and control brains. Neurochem Res 2000, 25:247-255.

29. Fuentealba RA, Liu Q, Zhang J, Kanekiyo T, Hu X, Lee JM, LaDu MJ, Bu G: Low-density lipoprotein receptor-related protein 1 (LRP1) mediates neuronal Abeta42 uptake and lysosomal trafficking. PLoS One 2010, 5:e11884.

30. Dominguez D, Tournoy J, Hartmann D, Huth T, Cryns K, Deforce S, Serneels L, Camacho IE, Marjaux E, Craessaerts K, et al: Phenotypic and biochemical analyses of BACE1- and BACE2-deficient mice. J Biol Chem 2005, 280:30797-30806.

31. Ahmed RR, Holler CJ, Webb RL, Li F, Beckett TL, Murphy MP: BACE1 and BACE2 enzymatic activities in Alzheimer's disease. J Neurochem 2010, 112:1045-1053.

32. Cheon MS, Dierssen M, Kim SH, Lubec G: Protein expression of BACE1, BACE2 and APP in Down syndrome brains. Amino Acids 2008, 35:339-343.

33. Holler CJ, Webb RL, Laux AL, Beckett TL, Niedowicz DM, Ahmed RR, Liu Y, Simmons CR, Dowling AL, Spinelli A, et al: BACE2 expression increases in human neurodegenerative disease. Am J Pathol 2012, 180:337-350.

34. Motonaga K, Itoh M, Becker LE, Goto Y, Takashima S: Elevated expression of beta-site amyloid precursor protein cleaving enzyme 2 in brains of patients with Down syndrome. Neurosci Lett 2002, 326:64-66.

35. Stockley $\mathrm{JH}$, O'Neill C: The proteins BACE1 and BACE2 and beta-secretase activity in normal and Alzheimer's disease brain. Biochem Soc Trans 2007, 35:574-576.
36. Stockley $\mathrm{JH}$, Ravid R, O'Neill C: Altered beta-secretase enzyme kinetics and levels of both BACE1 and BACE2 in the Alzheimer's disease brain. FEBS Lett 2006, 580:6550-6560.

37. Wyss-Coray T, Loike JD, Brionne TC, Lu E, Anankov R, Yan F, Silverstein SC, Husemann J: Adult mouse astrocytes degrade amyloid-beta in vitro and in situ. Nat Med 2003, 9:453-457.

38. Nilsson P, Iwata N, Muramatsu S, Tjernberg LO, Winblad B, Saido TC: Gene therapy in Alzheimer's disease - potential for disease modification. J Cell Mol Med 2010, 14:741-757.

39. LaFerla FM, Green KN, Oddo S: Intracellular amyloid-beta in Alzheimer's disease. Nat Rev Neurosci 2007, 8:499-509.

40. Zhao J, Li L, Leissring MA: Insulin-degrading enzyme is exported via an unconventional protein secretion pathway. Mol Neurodegener 2009, 4:4

41. Turner AJ: Exploring the structure and function of zinc metallopeptidases: old enzymes and new discoveries. Biochem Soc Trans 2003, 31:723-727.

42. Leuchtenberger S, Maler J, Czirr E, Ness J, Lichtenthaler SF, Esselmann H, Pietrzik CU, Wiltfang J, Weggen S: Nonsteroidal anti-inflammatory drugs and ectodomain shedding of the amyloid precursor protein. Neurodegener Dis 2009, 6:1-8.

43. Chen F, Eckman EA, Eckman CB: Reductions in levels of the Alzheimer's amyloid beta peptide after oral administration of ginsenosides. FASEB $J$ 2006, 20:1269-1271

44. Abdul-Hay SO, Luo J, Ashghodom RT, Thatcher GR: NO-flurbiprofen reduces amyloid-beta, is neuroprotective in cell culture, and enhances cognition in response to cholinergic blockade. J Neurochem 2009, 111:766-776.

45. Levites $Y$, Jansen $K$, Smithson LA, Dakin R, Holloway VM, Das P, Golde TE: Intracranial adeno-associated virus-mediated delivery of anti-pan amyloid beta, amyloid beta40, and amyloid beta42 single-chain variable fragments attenuates plaque pathology in amyloid precursor protein mice. J Neurosci 2006, 26:11923-11928.

46. Conboy JJ, Wood KG, Lame ME, Durham RA, Geoghegan KF: Modification of amyloid-beta(1-40) by a protease inhibitor creates risk of error in mass spectrometric quantitation of amyloid-beta(1-42). Anal Biochem 2008, 382:147-149.

doi:10.1186/1750-1326-7-46

Cite this article as: Abdul-Hay et al: Identification of BACE2 as an avid ß-amyloid-degrading protease. Molecular Neurodegeneration 2012 7:46.

\section{Submit your next manuscript to BioMed Central and take full advantage of:}

- Convenient online submission

- Thorough peer review

- No space constraints or color figure charges

- Immediate publication on acceptance

- Inclusion in PubMed, CAS, Scopus and Google Scholar

- Research which is freely available for redistribution 